\title{
Phonological and semantic processing during comprehension in Wernicke's aphasia: a N400 and Phonological Mapping Negativity study
}

Article

Accepted Version

Creative Commons: Attribution-Noncommercial-No Derivative Works 4.0

Robson, H., Pilkington, E., Evans, L., DeLuca, V. and Keidel, J. (2017) Phonological and semantic processing during comprehension in Wernicke's aphasia: a N400 and Phonological Mapping Negativity study. Neuropsychologia, 100. pp. 144-154. ISSN 0028-3932 doi:

https://doi.org/10.1016/j.neuropsychologia.2017.04.012 Available at https://centaur.reading.ac.uk/70109/

It is advisable to refer to the publisher's version if you intend to cite from the work. See Guidance on citing.

To link to this article DOI:

http://dx.doi.org/10.1016/j.neuropsychologia.2017.04.012

Publisher: Elsevier

All outputs in CentAUR are protected by Intellectual Property Rights law, including copyright law. Copyright and IPR is retained by the creators or other copyright holders. Terms and conditions for use of this material are defined in the End User Agreement. 


\section{www.reading.ac.uk/centaur}

\section{CentAUR}

Central Archive at the University of Reading

Reading's research outputs online 
Phonological and semantic processing during comprehension in Wernicke's aphasia: An N400 and Phonological Mapping Negativity Study.

ROBSON, Holly; ${ }^{*}$ PILKINGTON, Emma1; EVANS, Louise²; DELUCA, Vincent¹; KEIDEL, James L. ${ }^{3}$

1: School of Psychology and Clinical Language Sciences, University of Reading, UK 2: Oxford University Hospitals NHS Foundation Trust, UK 3: School of Psychology, University of Sussex, UK

* corresponding author

Holly Robson, h.v.robson@reading.ac.uk

School of Psychology and Clinical Language Sciences

Earley Gate, University of Reading,

Reading, RG6 6AL, UK

Funding: This research was funded by a Stroke Association Senior Research Training Fellowship [TSA SRTF2012/02] and a University of Reading Undergraduate Research Opportunities Placement scheme awarded to H. Robson and a Stroke Association Postgraduate Fellowship [TSA PGF 2015-02] awarded to E. Pilkington.

Acknowledgments: We would like to extend our thanks to all the participants and carers involved in the current study and to Elizabeth Shirley for her support with analysis. 


\section{$\underline{\text { Abstract }}$}

Comprehension impairments in Wernicke's aphasia are thought to result from a combination of impaired phonological and semantic processes. However, the relationship between these cognitive processes and language comprehension has only been inferred through offline neuropsychological tasks. This study used ERPs to investigate phonological and semantic processing during online single word comprehension.

EEG was recorded in a group of Wernicke's aphasia $n=8$ and control participants $n=10$ while performing a word-picture verification task. The N400 and Phonological Mapping Negativity/ Phonological Mismatch Negativity (PMN) event-related potential components were investigated as an index of semantic and phonological processing, respectively. Individuals with Wernicke's aphasia displayed reduced and inconsistent N400 and PMN effects in comparison to control participants. Reduced N400 effects in the WA group were simulated in the control group by artificially degrading speech perception. Correlation analyses in the Wernicke's aphasia group found that PMN but not N400 amplitude was associated with behavioural word-picture verification performance.

The results confirm impairments at both phonological and semantic stages of comprehension in Wernicke's aphasia. However, reduced N400 responses in Wernicke's aphasia are at least partially attributable to earlier phonological processing impairments. The results provide further support for the traditional model of Wernicke's aphasia which claims a causative link between phonological processing and language comprehension impairments. 


\section{Introduction:}

Wernicke's aphasia (WA) is an acquired syndrome associated with impaired auditory language comprehension in the presence of spared speech fluency (Goodglass, Kaplan et al., 2001a). In this study we use event related potentials (ERPs) to explore the timecourse of online single word comprehension in WA and control participants, and provide insights into the causes of auditory comprehension impairments in this population.

Computational, neuropsychological and neurobiological models of single word comprehension, although different in components and mechanisms, agree on two fundamental stages of comprehension: auditory-phonological and semantic analysis (Hickok \& Poeppel, 2007; Marslen-Wilson, 1987; McClelland \& Elman, 1986; Norris \& McQueen, 2008). Auditoryphonological processing forms the initial stages of comprehension in which the phonological form of the item is abstracted and analysed from the speech stream. Contemporary neurobiological models emphasise a hierarchical processing mechanism in which invariant phonological information is extracted from the acoustic signal by combining increasingly complex units of auditory information (Bizley \& Cohen, 2013; Giordano, McAdams et al., 2012). In the final, semantic processing stage, conceptual representations are accessed and analysed in context (Hagoort, Hald et al., 2004).

At the group level, WA is associated with damage to the superior and middle aspects of the posterior temporal lobe. In almost all cases the lesion extends beyond these core regions into inferior temporal, parietal and even frontal regions; however, involvement of these regions is inconsistent (Bogen \& Bogen, 1976; Ogar, Baldo et al., 2011; Robson, Sage et al., 2012). The left superior and middle temporal lobe are involved in acoustic-phonological processing and semantic analysis in neurotypical populations (Arsenault \& Buchsbaum, 2015; Humphries, Sabri et al., 2014; Krieger-Redwood \& Jefferies, 2014; Xu, Zhang et al., 2013), an observation 
consistent with the impairment profile observed in WA. Individuals with WA present with impairments of processing non-verbal auditory information in tasks such as frequency modulation detection, gap detection and frequency sweep discrimination (Divenyi \& Robinson, 1989; Fink, Churan et al., 2006; Robson, Grube et al., 2013) and phonological analysis, as measured by auditory discrimination tasks (Blumstein, Baker et al., 1977; Robson, Cloutman et al., 2014). Additionally, multimodal semantic impairments have been identified in the majority of WA cases using tasks such as semantic association, colour-picture matching, drawing from memory and synonym judgement (Cohen, Kelter et al., 1980; Gainotti, Silveri et al., 1983; Robson, Sage et al., 2012).

In recent work, we have demonstrated a significant relationship between phonological discrimination/auditory judgement tasks and language comprehension in WA participants (Robson, Keidel et al., 2012). These results provide support for the traditional model of WA, which hypothesises that disrupted acoustic-phonological processing impairs access to the semantic system (Luria, 1976; Luria \& Hutton, 1977). On this view, impairments to the auditory ventral stream following left hemisphere superior temporal lesions disrupt the ability of the auditory network to engage in normal hierarchical processing (Robson, Cloutman et al., 2014; Teki, Barnes et al., 2013). Therefore, auditory input to the semantic system may be noisy or poorly elaborated/abstracted, leading to difficulties in accurately accessing semantic representations. This type of perceptual access deficit is compounded in those individual with semantic impairments, who are less able to use top-down conceptual constraints to disambiguate such impoverished input.

Lesion and neuropsychological evidence suggests a central role of impaired auditory and phonological processing to the comprehension impairment in WA. This relationship, however, has only been identified through correlations between offline neuropsychological assessments, which have different processing requirements to the dynamics of online comprehension. As 
such, it is important to identify how phonological and semantic components are engaged during on-going, active comprehension. The high temporal resolution of ERPs provides a window into language comprehension as processing unfolds.

Two ERP components are of interest in the current study: the Phonological Mapping Negativity (PMN), alternatively discussed as the Phonological Mismatch Negativity, and the N400. The PMN is a negative deflection in the ERP waveform which occurs approximately $250 \mathrm{~ms}$ poststimulus onset in fronto-central regions (Connolly \& Phillips, 1994; Connolly, Phillips et al., 1992; Desroches, Newman et al., 2008; Newman, Connolly et al., 2003; Steinhauer \& Connolly, 2008), and is elicited when the phonological onset of a spoken word does not match the contextually expected phonology (Desroches, Newman et al., 2008; Newman, Connolly et al., 2003). Therefore, this component provides an index of the accuracy of phonological analysis and the early phase of comprehension. It should be noted that a similar or same early ERP negativity observed during auditory has alternatively been identified as the $\mathrm{N} 200$, a component also associated with auditory word recognition processes but interpreted as a reflection of early lexical-semantic processing (Van Den Brink, Brown et al., 2001). The N400 is associated with the later semantic processing stage and peaks in central-parietal regions between 200 and 600ms after stimulus onset (Kutas \& Federmeier, 2011). The N400 is thought to indicate the ease of integrating semantic information into context (Baggio \& Hagoort, 2011; Friederici, 2011) and/or retrieval of information from semantic memory (Baggio \& Hagoort, 2011; Brouwer \& Hoeks, 2013; Kuperberg, 2016). The magnitude of this component is modulated by two competing forces. Smaller N400s are found when semantic judgements are easier - a pair of congruent stimuli will elicit a smaller or no N400 in comparison to a pair of incongruent stimuli, because semantic analysis and access is easier in the first instance. The magnitude of the N400 is also reduced under degraded listening conditions (Aydelott, Baer-Henney et al., 2012; Carey, Mercure et al., 2014; Strauß, Kotz et al., 2013), an effect thought to reflect the reduced quality of the information reaching the semantic system (Aydelott, Dick et al., 2006). 
In this study we explore PMN and N400 responses in a group of individuals with WA and a group of control participants in order to investigate the phonological and semantic components of online language comprehension. We employ a word-picture verification task to investigate how the phonological and semantic systems respond to degrees of acoustic, phonological and semantic competition.

\section{Method:}

\section{Participants:}

Ethical approval was obtained from the University of Reading Ethics Committee. Eight individuals with Wernicke's-type aphasia (WA, mean age 66.4, SD 8.2, mean pure tone audiometry threshold 22.5, SD 14.0) and 10 age and peripheral hearing matched controls (mean age 67.6, SD 14.4, mean pure tone audiometry threshold 28.4, SD 17.4) were recruited from a panel of research volunteers. Control participants were screened using the ACE-III (Hsieh, Schubert et al., 2013) to confirm typical ageing (Table 1).

\section{WA Neuropsychological Profile and Lesion Profile:}

Individuals with WA were screened using the Boston Diagnostic Aphasia Examination - Short Form (Goodglass, Kaplan et al., 2001b) (Table 1), which was used in conjunction with the clinical opinion of a speech and language therapist to confirm diagnosis. Individuals displayed highly fluent speech, with the exception of P4 and P5, who had somewhat reduced fluency. All individuals displayed impaired language comprehension at the phrase and sentence level, and all but P7 displayed single word auditory comprehension impairments. All individuals displayed some difficulties with repetition, producing phonological errors. Therefore, all individuals presented within the fuzzy boundary of WA but along a spectrum of severity across symptom dimensions. 
Table 1: Participant Diagnostics

\begin{tabular}{|c|c|c|c|c|c|c|c|c|c|}
\hline & \multicolumn{5}{|c|}{ BDAE-Short Form } & \multirow[b]{3}{*}{ Imaging } & & \multirow[b]{3}{*}{ Pt. No. } & \multirow[b]{3}{*}{ ACE-III } \\
\hline & $\mathrm{Pt}$ & Comp. & Rep. & & & & & & \\
\hline & No. & Centile & Centile & Fluency & sWPM & & & & \\
\hline \multirow{10}{*}{ 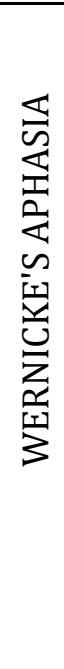 } & 1 & 28 & 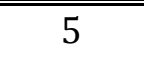 & 100 & 37 & Clin MRI & \multirow{10}{*}{$\begin{array}{l}\overrightarrow{0} \\
\text { 足 } \\
z \\
0 \\
0\end{array}$} & 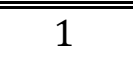 & 93 \\
\hline & 2 & 25 & 30 & 100 & 44 & Clin CT & & 2 & 87 \\
\hline & 3 & 7 & 35 & 100 & 34 & Clin CT & & 3 & 91 \\
\hline & 4 & 33 & 10 & 55 & 29 & NA & & 4 & 91 \\
\hline & 5 & 9 & 7 & 42 & 31 & 3T MRI & & 5 & 88 \\
\hline & 6 & 13 & 5 & 100 & 41 & Clin CT & & 6 & 88 \\
\hline & 7 & 67 & 60 & 100 & 46 & 3T MRI & & 7 & 94 \\
\hline & \multirow[t]{3}{*}{8} & 50 & 80 & 100 & 42 & Clin MRI & & 8 & 88 \\
\hline & & & & & & & & 9 & 89 \\
\hline & & & & & & & & 10 & 95 \\
\hline
\end{tabular}

BDAE = Boston Diagnostic Aphasia Examination (Goodglass et al., 2001); sWPM = spoken word-picture matching, italicised font indicates outside normal limits; ACE-III = Addenbrooks Cognitive Examination (Hseih et al., 2013); Pt = participant. NA not available

Clinical CTs or MRIs were available for 5 WA participants and 3T T1-weighted research MRIs were available for two further WA participants, Table 1. Lesions from clinical imaging were delineated manually by lesion drawing in native space. Individual lesion maps were then used for cost-function masking during normalisation, implemented in the SPM clinical toolbox (Rorden, Bonilha et al., 2012) and, subsequently, normalisation parameters were applied to the lesion images to transform these to native space. Lesion delineation in 3T research MRI scans was implemented in the ALI toolbox (Seghier, Ramlackhansingh et al., 2008) by comparing WA participant scans to 11 elderly controls scans. Finally, binary lesion masks were combined to create a lesion overlap map, Figure 1.

Peak lesion overlap (6/7 participants) was observed in the posterior superior temporal sulcus (STS) and white matter of the posterior middle temporal gyrus (MTG) in the left hemisphere. 
High overlap (5/7 participants) was observed in the posterior superior temporal gyrus (STG) and temporoparietal junction and middle to anterior STG and STS. At an individual level all participants had some involvement of the MTG and STS.

Figure 1: Lesion overlap map for 7/8 WA participants.

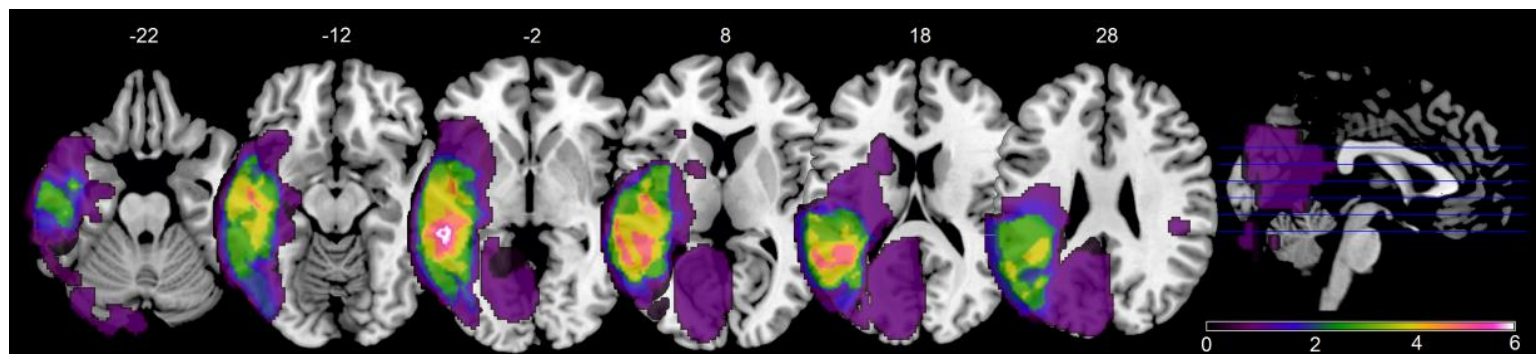

Lesion overlap map created in MRIcron (Rorden, 2007). Colours indicate number of participants with a lesion at each voxel. MNI z coordinates are displayed above slices.

\section{ERP Methodology:}

\section{ERP Experiment:}

Following Desroches et al., (2008), the ERP experiment consisted of a word-picture verification task, presented through the E-Prime 2.0 software (Psychology Software Tools, Inc), in which the participant judged whether a picture and spoken word were the same or different (a schematic is presented in Figure 2). A picture was presented on screen for $1 \mathrm{~s}$, followed by a second presentation screen of $1 \mathrm{~s}$ on which the picture remained and a spoken word was presented free field (i.e., without headphones). This was followed by a $2.5 \mathrm{~s}$ response screen during which the participant was required to make their response by pressing one of two buttons on an external number pad. All responses were made with the left hand. Following the response screen, an inter-trial fixation of roved duration between $2 \mathrm{~s}$ and $4 \mathrm{~s}$ was presented. The experiment consisted of 240 trials split into blocks of 40 trials. After each block the participant was encouraged to rest and move and to re-start the experiment when they were ready. A behavioural version of the experiment was additionally administered because the short 
response time window resulted in a number of "no responses" in the WA group. This experiment had a consistent inter-trial fixation of $500 \mathrm{~ms}$ and no time limit to the response screen for the WA participants. One control and one WA participant did not undertake the behavioural version.

Details and examples of experimental trials are presented in Table 2. Participants were presented with 240 trials in total. 120 of these trials were the same in the WA and control group: 40 congruent trials (controls: congruent clear, WA: congruent set 1), 40 phonological near incongruent trials (e.g. toaster-poster) and 40 semantic near incongruent trials (e.g. brushcomb). All phonological incongruents had a word initial phoneme change which differed by one distinctive feature; this condition is henceforth referred to as phonological near/clear. All semantic incongruents displayed a high associative relationship with the picture item, the mean latent semantic analysis relationship between the target picture items and incongruent spoken word was $0.36, \mathrm{SD}=0.18$ (Landauer, Foltz et al., 1998), this condition is henceforth referred to as semantic near/clear. Additional group specific items are described below. There was no significant difference in frequency between conditions, however, imageability was lower in the phonological than semantic condition $(2 \times 2$ ANOVA condition $\mathrm{x}$ distractor type: main effect condition $\left.\mathrm{F}_{(1,49)}=11.54, \mathrm{p}=0.001\right)$.

Table 2: ERP task conditions and item number by group

\begin{tabular}{|c|c|c|c|c|c|c|c|c|}
\hline \multirow[b]{3}{*}{ Group } & \multirow{3}{*}{$\begin{array}{l}\text { Cong. } \\
\text { Clear }\end{array}$} & \multirow{3}{*}{$\begin{array}{l}\text { Cong. } \\
\text { Degraded }\end{array}$} & \multirow{3}{*}{$\begin{array}{l}\text { Phon. Far } \\
\text { Clear }\end{array}$} & \multirow{3}{*}{$\begin{array}{l}\text { Phon. } \\
\text { Near } \\
\text { Clear }\end{array}$} & \multicolumn{2}{|l|}{ Phon. } & \multirow[b]{2}{*}{ Sem. Near } & \multirow{3}{*}{$\begin{array}{l}\text { Sem. Near } \\
\text { Degraded }\end{array}$} \\
\hline & & & & & Near & Sem. Far & & \\
\hline & & & & & Degraded & Clear & Clear & \\
\hline Control & 40 & 40 & & 40 & 40 & & 40 & 40 \\
\hline WA & 80 & & 40 & 40 & & 40 & 40 & \\
\hline Example & \multicolumn{2}{|c|}{ bottle - bottle } & cap - map & \multicolumn{2}{|c|}{ rake - lake } & tea-water & van - lorry & \\
\hline
\end{tabular}




\section{Control ERP experiment variation:}

Control participants were additionally exposed to 120 trials (40 congruent, 40 phonological incongruent and 40 semantic incongruent) in a degraded listening condition. These trials used Saberi speech, created using the Praat software (Boersma \& Weenink, 2009). Saberi speech disrupts the temporal structure of speech by temporally reversing segments of speech, but retaining the overall order of the segments (Saberi \& Perrott, 1999). This study used a segment length of $35 \mathrm{~ms}$, which was found to produce an accuracy rate of approximately $70 \%$ during pilot testing. The Saberi speech condition was included to simulate the auditory processing impairment present in WA. These conditions are henceforth referred to as phonological degraded and semantic degraded.

Figure 2: Example of Word-Picture Verification Trial

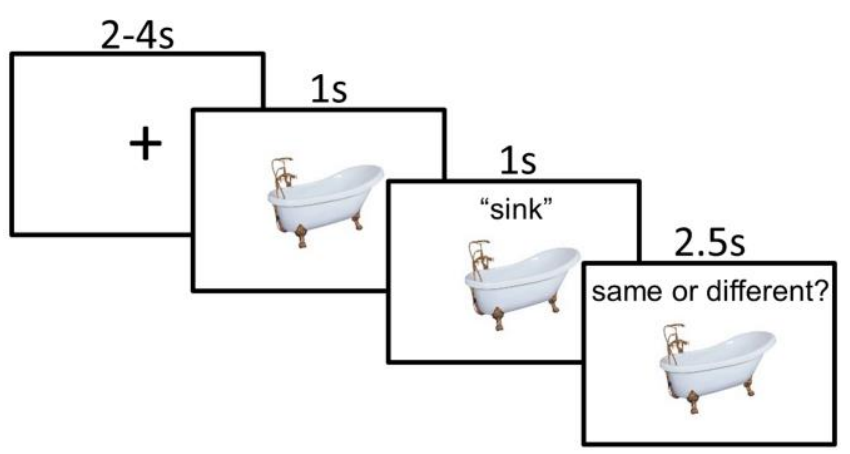

WA ERP experiment variation:

WA participants were also exposed to an additional 120 trials (40 congruent - set 2, 40 phonological far and 40 semantic far), all presented without distortion. These incongruent items were more distantly related to the target than in the near conditions and are henceforth referred to as phonological far and semantic far incongruents. The phonological far incongruents differed by two or three distinctive features (e.g. soap-rope) and the semantic far incongruents displayed significantly smaller latent semantic analysis distances $(\mathrm{M}=0.24, \mathrm{SD}=$ $0.16)$ than the semantic near incongruents $\left(\mathrm{t}_{(78)}=3.1, \mathrm{p}=0.003\right)$. 
ERP Data Collection and Analysis:

ERP data were collected over 64 electrodes in 10-20 configuration (EasyCap, BrainProducts) using the Brain Vision Amplifier (BrainAmp) and Brain Vision Recorder software (BrainProducts). $\mathrm{AFz}$ and $\mathrm{FCz}$ formed the ground and reference electrodes, respectively. EEG data were collected at a sampling rate of $512 \mathrm{~Hz}$ with a $50 \mathrm{~Hz}$ notch filter. Electrode impedance was kept below $20 \Omega$. Where impedance could not be brought below $20 \Omega$, channels were turned off and data from that channel were interpolated during analysis. No participant required interpolation of more than three channels. ERP data were pre-processed in EEGlab (version 12.01.0). Pre-processing consisted of downsampling to $250 \mathrm{~Hz}$, bandpass filtering between $0.3-$ $25 \mathrm{~Hz}$ using IIR non-casual filter robust to phase shift, average re-referencing, epoching between -200 and $800 \mathrm{~ms}$ from the onset of the spoken word and baseline correction. Independent component analysis using the extended runICA algorithm (Lee, Girolami et al., 1999) was used to remove eye movements and artefacts. Finally, automatic epoch rejection was used to remove epochs containing amplitudes of $>100 \mu \mathrm{V}$. Epochs were averaged over condition and exported to Excel for further analysis.

ERP Data Analysis:

ERP data were extracted from the Phonological Mapping Negativity (PMN) and N400 time windows (160-260ms and 300-500ms, respectively). These time windows are consistent with previous research (Desroches, Newman et al., 2008; Kiefer, 2002; Newman \& Connolly, 2009) and conformed to effects observable in the grand average waveforms (Figs. 3-6). PMN data were taken from frontal electrodes (Fz and F1-6) and N400 data were taken from centralparietal electrodes (POz, P01-4, Pz, P1-4). Statistical analysis used ANOVA to identify group, condition and distractor type effects on ERP mean amplitude. Individual level effects were explored across the case series using time-series data. 
Results:

Results from the behavioural version of the word-picture verification experiment and N400 and PMN mean amplitude results are displayed in Tables 3, 4 and 5. Figures 3-6 display N400 and PMN waveforms across conditions and groups.

Figure 3: ERP Waveforms in Phonological Conditions in the Control Group
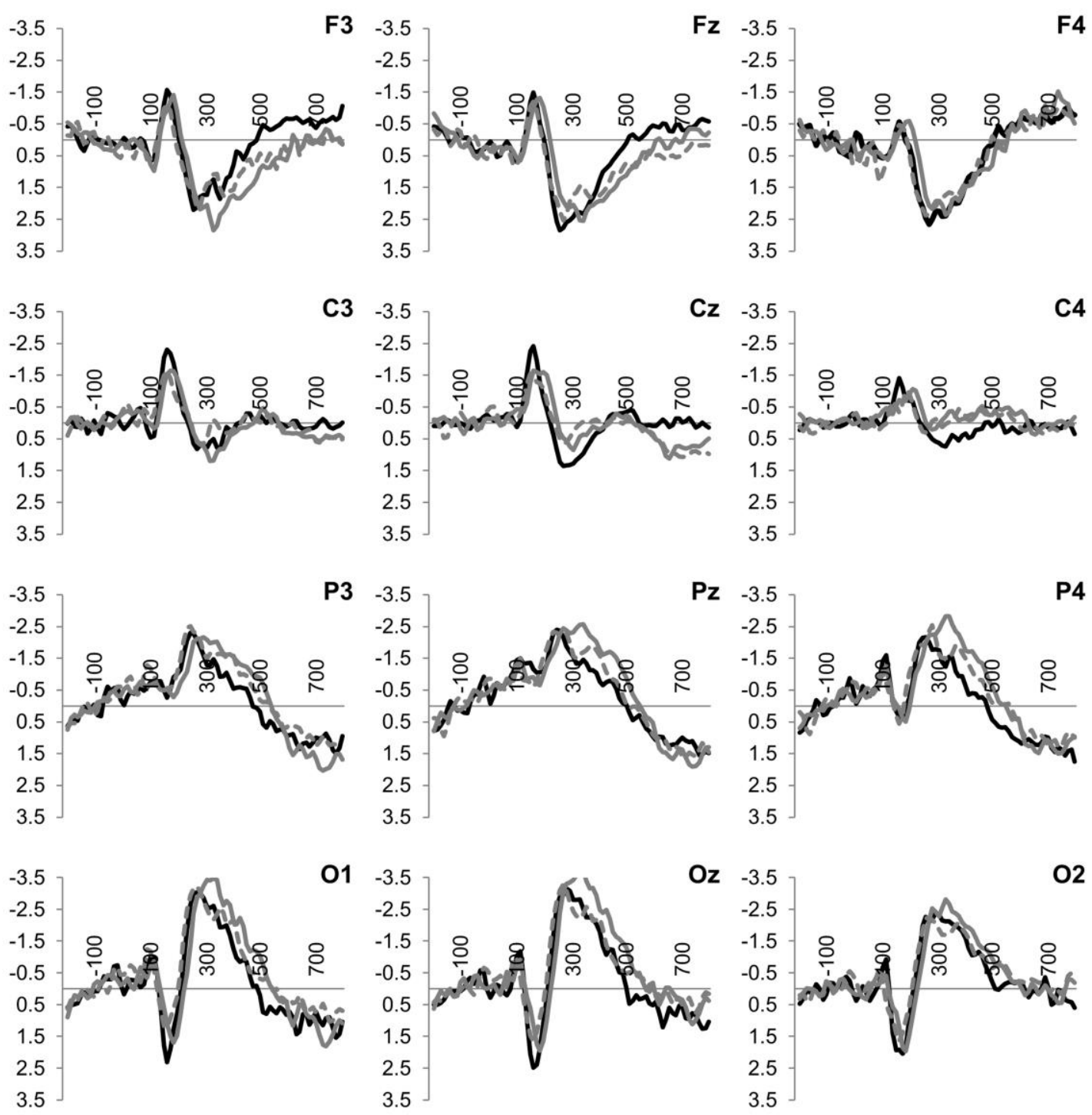

— cong. clear phon. clear ---phon. degraded

ERPs displayed for frontal, central, parietal and occipital electrodes in the semantic conditions. Amplitude in $\mu \mathrm{V}$, time locked to onset of word stimulus. 
Figure 4: ERP Waveforms in Semantic Conditions in the Control Group
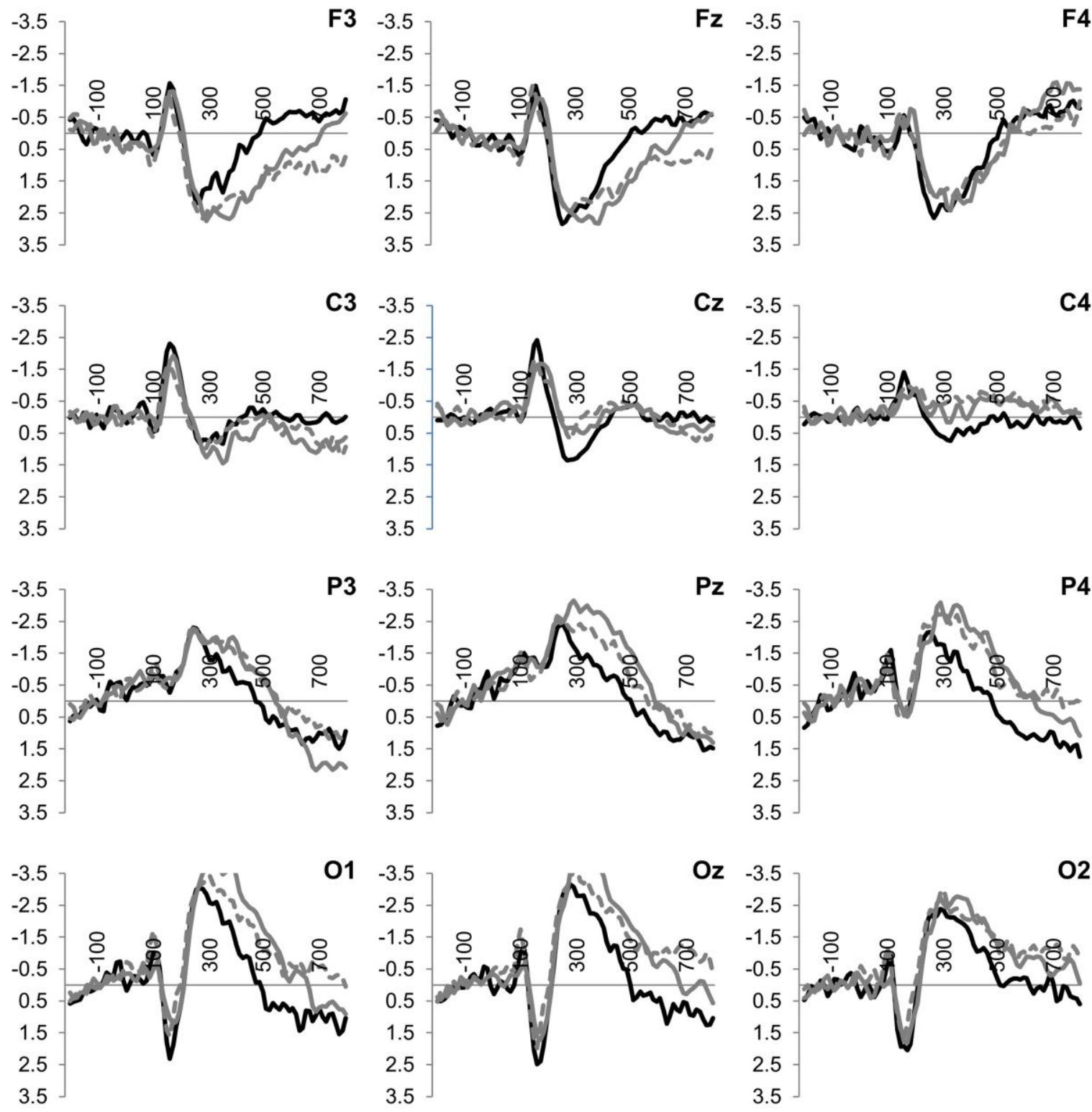

- cong. clear

sem. clear - --sem. degraded

ERPs displayed for frontal, central, parietal and occipital electrodes in the semantic conditions. Amplitude in $\mu \mathrm{V}$, time locked to onset of word stimulus.

Behavioural Results:

All WA aphasia participants were able to engage with the word-picture verification task, however, one participant (P3) performed at chance on the behavioural version of the task; 
however this participant was able to engage with the EEG task and was retained in the analysis. A 2 (Group: WA and controls) x 3 (Condition: congruents, near phonological incongruents, near semantic incongruents) ANOVA showed a significant main effect of Group $(F(1,14)=8.0$, $\mathrm{p}=0.014)$, reflecting greater overall accuracy in the control group than WA group, and a significant main effect of Condition $(F(2,28)=7.9, p=0.002)$, reflecting greater accuracy in the congruent condition than incongruent conditions in both groups. A significant group $\mathrm{x}$ condition interaction was also found $(\mathrm{F}(2,28)=4.4, \mathrm{p}=0.022)$; this was caused by significantly poorer performance by the control group in the phonological condition in comparison to the congruent condition $\left(\mathrm{t}_{(8)}=2.7, \mathrm{p}=0.027\right)$ whereas the WA group displayed significantly poorer accuracy in the semantic condition than the congruent condition $\left(\mathrm{t}_{(6)}=2.7, \mathrm{p}=0.036\right)$.

A 3 (Condition: congruent, phonological incongruent, semantic incongruent) x 2 (Distance: near incongruent and far incongruent) ANOVA explored the effect of phonological and semantic distance on behavioural accuracy in the WA group. A significant main effect of distance was found $(F(1,6)=44.9, p=0.001)$, reflecting high accuracy for far incongruent trials. Additionally, a condition $\mathrm{x}$ distance interaction was found $(\mathrm{F}(2,12)=7.3, \mathrm{p}=0.009)$, driven by significantly poorer performance in the semantic near incongruent condition than in the congruent condition-no other differences between the congruent condition and any other incongruent conditions were observed.

A 3 (condition: congruent, phonological incongruent, semantic incongruent) x 2 (speech type: clear, degraded) ANOVA explored the effect degraded speech on behavioural accuracy in the control group. In addition to the established main effect of condition, a significant main effect of speech type was identified $(F(1,8)=8.8, p=0.018)$, caused by poorer accuracy in the degraded listening conditions. Additionally, a condition $\mathrm{x}$ speech type interaction was identified $(F(2,16)=6.0, p=0.011)$, driven by a greater impact of degraded speech on accuracy in the phonological condition than in the other conditions. 
Table 3: Word-Picture Verification Accuracy - Behavioural Version

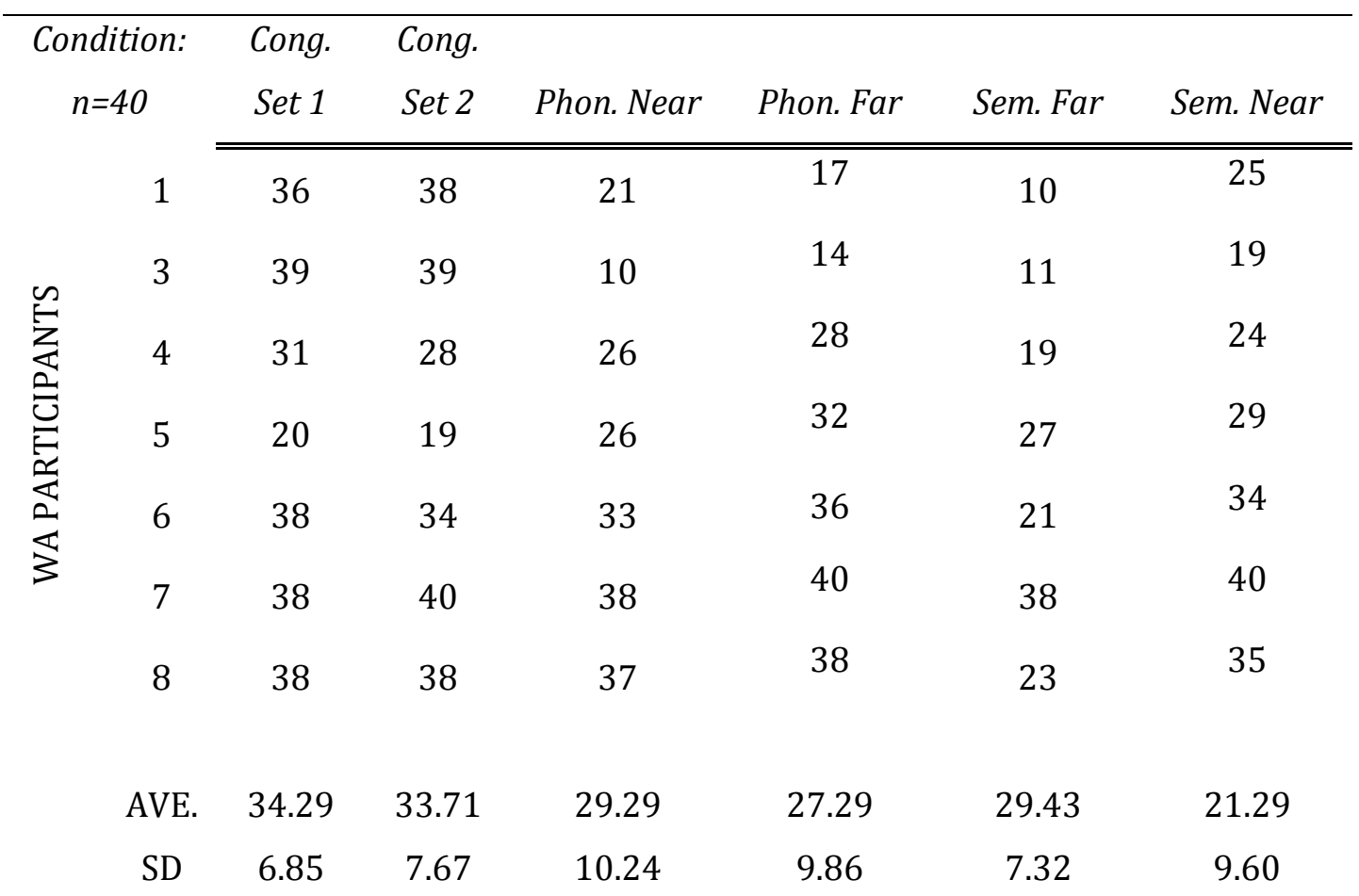

Condition: Cong. Cong. Phon. Near Phon.Near Sem.Near Sem.Near

\begin{tabular}{|c|c|c|c|c|c|c|}
\hline$n=40$ & Clear & Noise & Clear & Degraded & Clear & Degraded \\
\hline 1 & 37 & 38 & 38 & 38 & 38 & 37 \\
\hline 2 & 36 & 37 & 32 & 26 & 36 & 36 \\
\hline 3 & 38 & 37 & 36 & 31 & 33 & 36 \\
\hline 5 & 40 & 39 & 34 & 29 & 35 & 32 \\
\hline 6 & 39 & 39 & 35 & 21 & 33 & 30 \\
\hline 7 & 40 & 40 & 38 & 34 & 37 & 33 \\
\hline 8 & 28 & 30 & 24 & 26 & 33 & 33 \\
\hline 9 & 36 & 37 & 20 & 16 & 31 & 27 \\
\hline 10 & 37 & 35 & 35 & 32 & 38 & 35 \\
\hline AVE. & 36.78 & 36.89 & 32.44 & 28.11 & 34.89 & 33.22 \\
\hline SD & 3.63 & 2.98 & 6.29 & 6.74 & 2.52 & 3.23 \\
\hline
\end{tabular}

Accuracy from the behavioural variant of the word-picture verification experimental task. $\mathrm{N}=40$ trials/condition. Complete data are unavailable for WA participant 2 and control participant 4. 


\section{N400 Effects in WA and Controls:}

Initial analysis investigated whether N400 effects were present in each condition in the WA and control groups. Paired t-tests compared the average amplitude over the N400 window in each incongruent condition to the average amplitude in the congruent condition (clear set in control, half set in WA). The control group displayed significant N400 effects in the both semantic conditions, the phonological clear condition and a borderline significant N400 effect in the phonological degraded condition (phon. clear $t_{(9)}=3.7, p=0.005$; phon. degraded $t_{(9)}=2.2$, $\mathrm{p}=0.052$; sem. clear $\mathrm{t}_{(9)}=4.8, \mathrm{p}=0.001$; sem. degraded $\mathrm{t}_{(9)}=2.6, \mathrm{p}=0.028$ ). The WA group displayed a significant $\mathrm{N} 400$ effect in the phonological far condition $\left(\mathrm{t}_{(7)}=2.5, \mathrm{p}=0.038\right)$ and a borderline significant effect in the semantic far condition $\left(t_{(7)}=2.0, p=0.089\right)$ but no significant $\mathrm{N} 400$ effects in either the phonological or semantic near conditions (phon. near $t_{(7)}=0.74, p>0.05$; sem. near $\left.\mathrm{t}_{(7)}=1.1, \mathrm{p}>0.05\right)$.

N400 effects were investigated across the case series by performing paired t-tests on the time series amplitude data across the N400 window averaged across trials. In the control group all participants displayed significant $\mathrm{N} 400$ effects in the semantic clear condition; 8/10 participants displayed significant N400 effects in the phonological clear and semantic degraded conditions and 4/10 participants displayed N400 effects in the phonological degraded condition. In the WA group significant N400 effects were found in $6 / 8$ participants in the phonological near condition, 5/8 participants in the semantic far condition and 4/8 participants in both the phonological and semantic far conditions. 
Figure 5: ERP Waveforms in Phonological Conditions in the Aphasia Group

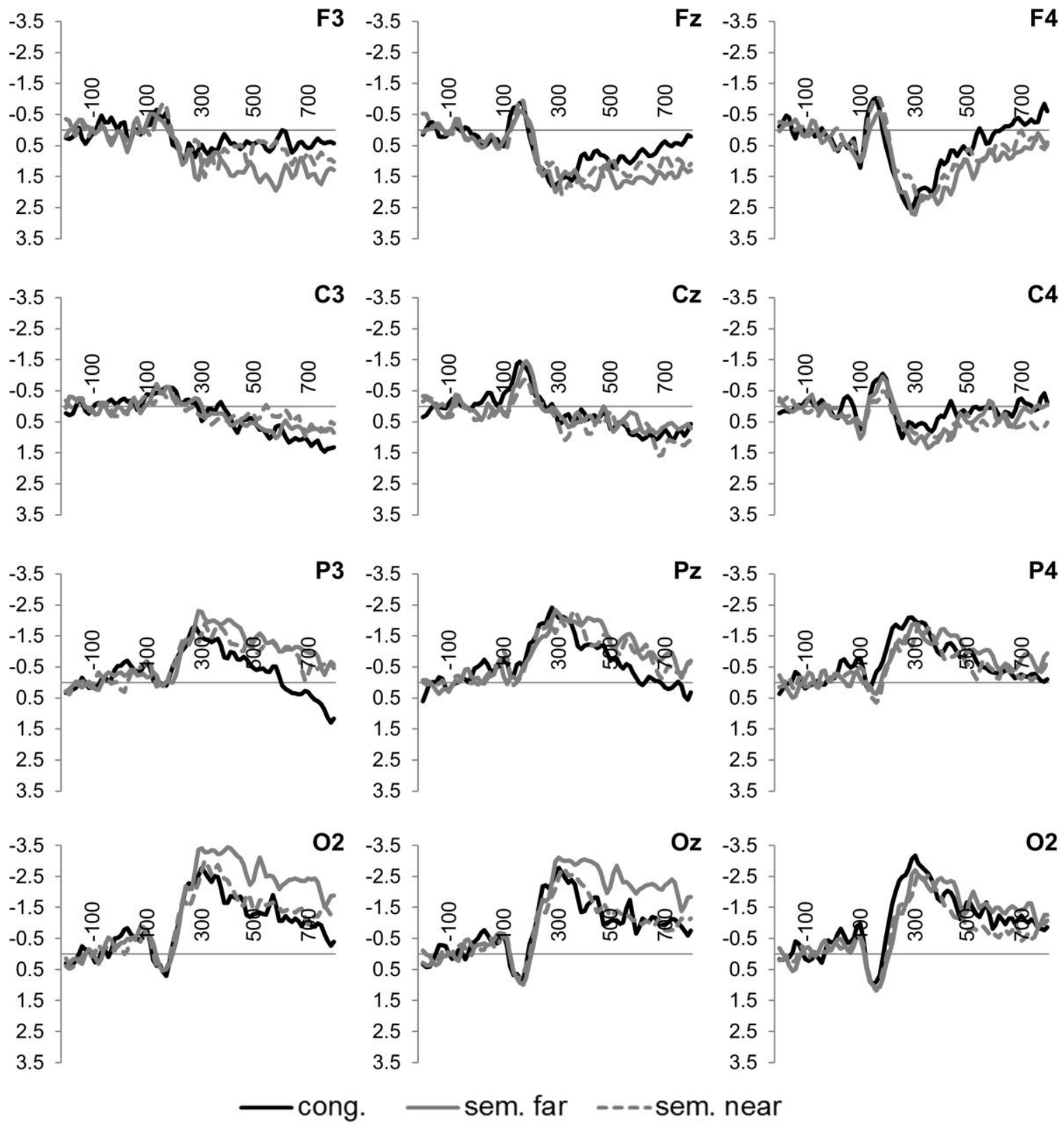

ERPs displayed for frontal, central, parietal and occipital electrodes in the semantic conditions. Amplitude in $\mu \mathrm{V}$, time locked to onset of word stimulus.

Comparison of N400 Effects between WA and Controls:

The WA and control groups were both presented congruent, phonological near and semantic near incongruents ( $\mathrm{n}=40 /$ condition) in clear speech. Difference waves were created by subtracting congruent from incongruent trials and a 2 (group: WA vs. control) x 2 (condition: 
phonological vs. semantic difference waves) ANOVA was used to compare mean N400 amplitude across group and condition. A main effect of group was found $(F(1,16)=7.6, p=0.014)$, confirming reduced $\mathrm{N} 400$ responses in $\mathrm{WA}$ and a main effect of condition $(\mathrm{F}(1,16)=8.0$, $\mathrm{p}=0.012$ ) as a result of larger $\mathrm{N} 400$ amplitudes in the semantic condition across both groups.

Effects of Phonological and Semantic Competition on N400 in WA:

At the group level and case series level greater N400 effects were found when the "distance" between picture items and incongruent words was greater in both the semantic and phonological condition. This was confirmed using a 2 (condition: phonological vs. semantic) x 2 (distance: near vs. far incongruent) ANOVA analysing the mean difference wave amplitude. A significant main effect of distance $(F(1,7)=7.1, p=0.033)$ was found, but no main effect of condition or interaction.

\section{Effects of Degraded Speech on N400 in Controls:}

The control group displayed smaller N400 amplitudes in both degraded incongruent conditions in comparison to the clear speech conditions. This was verified using a 2 (condition: phonological vs. semantic) x 2 (speech type: clear vs. degraded) ANOVA using mean difference wave amplitude. A significant main effect of speech type was identified $(F(1,9)=24.9, p=0.001)$, confirming reduced $\mathrm{N} 400$ responses in degraded condition, alongside a main effect of condition $(F(1,9)=9.5, p=0.013)$ caused by significantly greater $N 400$ responses in semantic conditions. 
Table 4: Mean N400 Difference Wave Amplitude by Condition

\begin{tabular}{|c|c|c|c|c|}
\hline Condition: & Phon. Near & Phon. Far & Sem. Near & Sem. Far \\
\hline 1 & 0.07 & -0.10 & 0.58 & -0.20 \\
\hline 2 & -0.35 & -0.58 & -0.88 & -1.58 \\
\hline $\mathscr{H}$ & -1.20 & -0.96 & -0.88 & -0.40 \\
\hline 玄 & 0.62 & 0.14 & 0.63 & 0.01 \\
\hline$\underline{\underline{0}}$ & 0.33 & -1.31 & -0.12 & -0.07 \\
\hline$\underline{E}$ & 0.60 & 0.31 & 0.26 & -0.03 \\
\hline 胥 & -0.57 & -0.74 & -0.58 & -0.41 \\
\hline$\sum_{3}^{\infty}$ & -0.98 & -1.29 & -1.08 & -2.68 \\
\hline AVE. & -0.18 & -0.57 & -0.26 & -0.67 \\
\hline $\mathrm{SD}$ & 0.70 & 0.63 & 0.69 & 0.96 \\
\hline
\end{tabular}

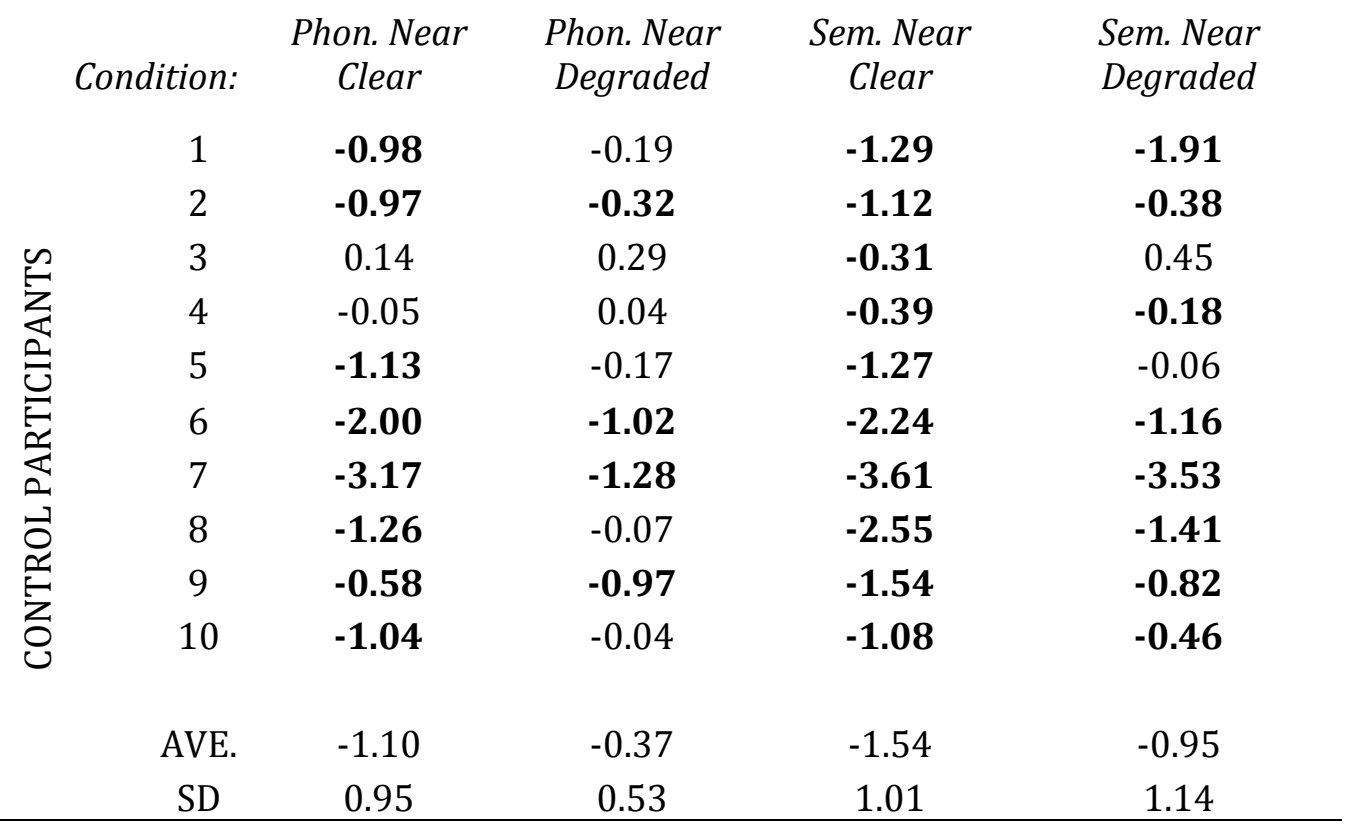

Bold font indicates significant individual N400 effect

Overall PMN Effects in WA and Controls:

Paired t-tests were used to explore PMN effects in each condition in each group. The average amplitude over the PMN window in the incongruent conditions was compared to the average amplitude in the congruent condition. The control group displayed significant PMN effects in the phonological clear condition $\left(\mathrm{t}_{(9)}=6.1, \mathrm{p}<0.001\right)$ and semantic clear condition $\left(\mathrm{t}_{(9)}=2.4\right.$, $\mathrm{p}=0.038$ ) but no significant PMN responses in either degraded condition (phon. degraded 
$t_{(9)}=0.4, p>0.05$; sem. degraded $t_{(9)}=0.9, p>0.05$ ). No significant PMN effects were found at the group level for the WA participants (all t-values $<1$ ).

PMN effects were investigated across the case series by performing paired t-tests on the time series amplitude data across the PMN window. In the control group 9/10 participants displayed significant PMN effects in the phonological clear condition, 6/10 participants displayed PMN effects in both semantic conditions (clear and degraded) and 3/10 participants displayed

Table 5: Mean PMN Difference Wave Amplitude by Condition

\begin{tabular}{|c|c|c|c|c|c|}
\hline \multicolumn{2}{|c|}{ Condition: } & Phon. Near & Phon. Far & Sem. Near & Sem. Far \\
\hline \multirow{8}{*}{ 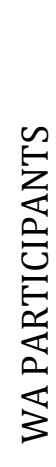 } & 1 & 0.41 & 0.07 & -0.49 & 1.24 \\
\hline & 2 & -0.58 & -1.55 & 0.04 & -0.06 \\
\hline & 3 & -0.05 & 0.20 & -0.25 & -0.26 \\
\hline & 4 & 0.41 & -0.32 & -0.84 & -0.55 \\
\hline & 5 & 0.52 & 1.28 & 0.85 & 0.83 \\
\hline & 6 & -0.09 & -0.30 & -0.29 & -0.12 \\
\hline & 7 & -1.62 & -1.15 & -1.81 & -2.11 \\
\hline & 8 & -0.64 & -0.09 & 1.29 & 0.95 \\
\hline & AVE. & -0.21 & -0.23 & -0.19 & -0.01 \\
\hline & SD & 0.72 & 0.86 & 0.96 & 1.07 \\
\hline
\end{tabular}

\begin{tabular}{|c|c|c|c|c|}
\hline Condition: & $\begin{array}{c}\text { Phon. Near } \\
\text { Clear }\end{array}$ & $\begin{array}{c}\text { Phon. Near } \\
\text { Degraded }\end{array}$ & Sem. Near Clear & $\begin{array}{l}\text { Sem. Near } \\
\text { Degraded }\end{array}$ \\
\hline 1 & -1.33 & 0.49 & -0.81 & -0.20 \\
\hline 2 & -0.33 & 0.11 & -0.57 & 0.14 \\
\hline 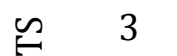 & -0.59 & -0.31 & -0.40 & -0.46 \\
\hline z & -0.85 & -0.30 & -0.28 & -0.10 \\
\hline 气 & -0.53 & -0.16 & -0.21 & -0.52 \\
\hline$\underset{\underline{x}}{\overrightarrow{\underline{x}}}$ & -0.39 & 0.42 & 0.46 & -0.32 \\
\hline$\overleftrightarrow{\Omega}$ & -0.44 & -1.01 & -0.18 & 0.71 \\
\hline $\overrightarrow{0}$ & -0.87 & 0.52 & -0.28 & -0.28 \\
\hline 鹪 & -1.27 & -1.20 & -1.41 & -1.01 \\
\hline రิ & -0.42 & 0.58 & -0.08 & 0.61 \\
\hline AVE. & -0.70 & -0.09 & -0.38 & -0.14 \\
\hline SD & 0.36 & 0.64 & 0.49 & 0.52 \\
\hline
\end{tabular}

Bold font indicates significant individual PMN effect 
significant PMN effects in the phonological degraded condition. In the WA group significant PMN effects were found in $4 / 8$ participants in the phonological far condition and $3 / 8$ participants in the phonological and semantic near conditions and 2/8 in the semantic far condition. Two participants displayed no significant PMN effect in any condition (Table 5).

Comparison of PMN Effects between WA and Controls:

PMN effects were compared between the WA and control groups with a 2x2 ANOVA (group $\mathrm{x}$ condition) using mean difference wave amplitude data. There were no significant main effects of condition, group or significant interaction.

Effects of Phonological and Semantic Competition on PMN in WA:

The effect of phonological and semantic "distance" on mean PMN difference wave amplitude in WA was investigated with a $2 \times 2$ ANOVA (condition vs. distance). There were no significant main effects of condition, distance or significant interaction.

Effects of Degraded Speech on PMN in Controls:

The effects of degraded speech on mean PMN difference wave amplitude in the control group that was investigated with a 2x2 ANOVA (condition vs. speech type). A significant main effect of speech type was observed $(F(1,9)=11.4, p=0.008)$ but no main effect of condition or interaction.

Behavioural Correlations in WA:

In the WA group, pearson's correlations were performed between behavioural version wordpicture verification accuracy (WPV), spoken word-picture matching (sWPM) accuracy and N400 and PMN difference wave amplitudes from the phonological and semantic conditions. Significant inverse correlations were found PMN amplitude in the phonological conditions and 
Figure 6: ERP Waveforms in Semantic Conditions in the Aphasia Group

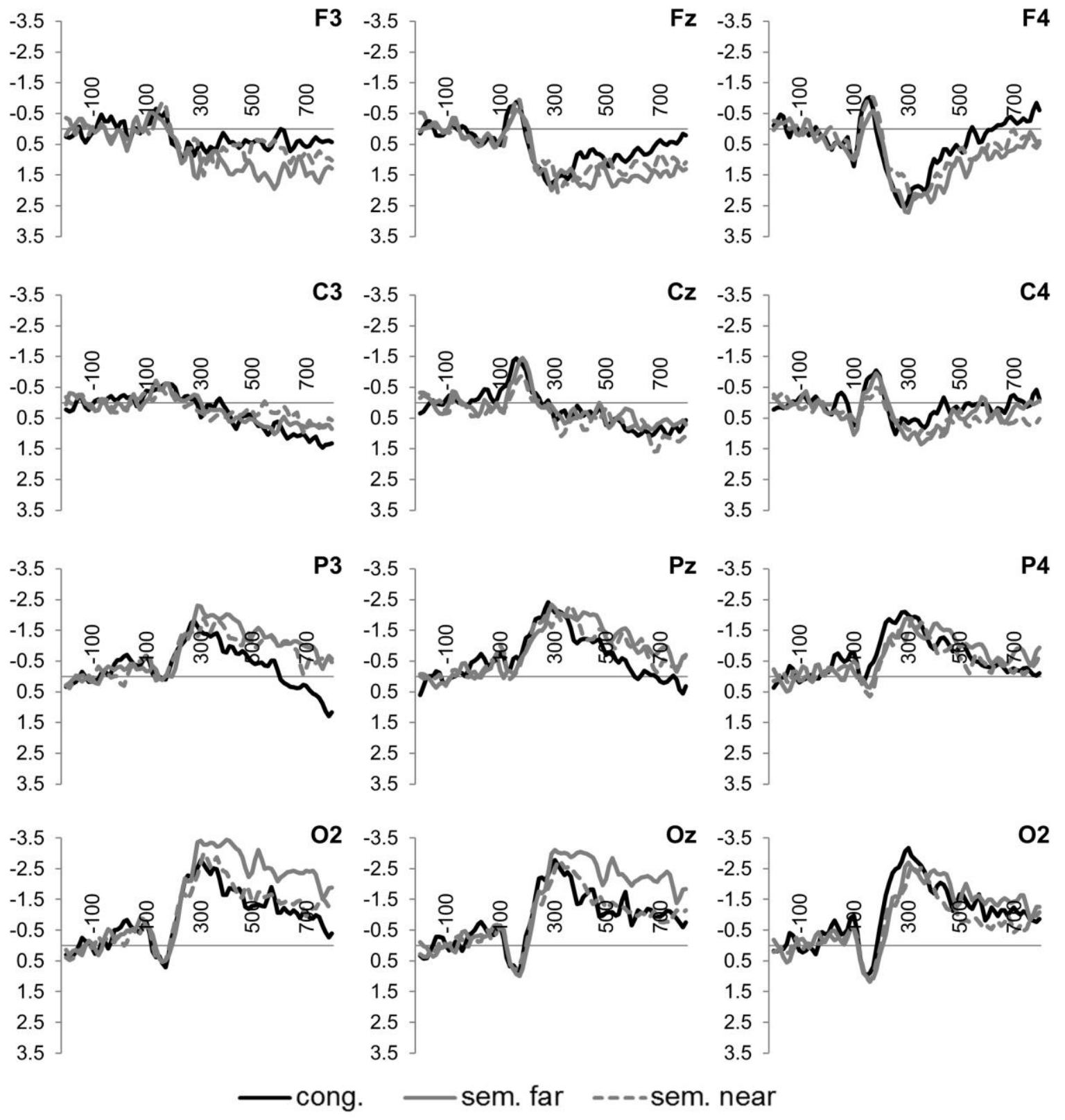

ERPs displayed for frontal, central, parietal and occipital electrodes in the semantic conditions. Amplitude in $\mu \mathrm{V}$, time locked to onset of word stimulus.

WPV accuracy ( $r=-0.81, \mathrm{df}=7, \mathrm{p}=0.026)$ and $\mathrm{sWPM}$ accuracy $(\mathrm{r}=-0.85, \mathrm{df}=7, \mathrm{p}=0.007)$, indicating that the greater the PMN response better behavioural performance. Effect sizes remained medium-large when peripheral hearing thresholds were controlled for (WPV r=-0.76; sWPM r=0.84). There was no relationship between behavioural scores and N400 amplitude. 


\section{Discussion:}

This study used ERPs to investigate phonological and semantic processes during single word comprehension in Wernicke's aphasia (WA). Results indicated impairments in both phonological (PMN) and semantic (N400) stages of comprehension; however, results from the control group suggested that impairments at the semantic processing/N400 stage are partially attributable to earlier disruption in speech perception. Correlation analyses indicated a direct relationship between phonological/PMN responses and single word comprehension capacity in WA.

A word-picture verification paradigm was used to explore $\mathrm{N} 400$ incongruence effects. Individuals with WA judged congruent, phonologically incongruent (near and far incongruents) and semantically incongruent (near and far incongruents) trials while control participants judged congruent, phonologically and semantically incongruent trials (all near incongruents), half of which were presented with a degraded auditory component. The control group displayed significant group- and individual-level N400 effects. In contrast, N400 effects were less consistent across the WA case series and borderline group level effects were only identified with easier phonological and semantic judgements (far conditions). Statistical comparison of the WA and control groups confirmed reduced N400 responses in WA. This mirrors previous research in which reduced N400 responses have been identified in aphasia in both single word and sentence level paradigms (Hagoort, Brown et al., 1996; Kawohl, Bunse et al., 2009; Swaab, Brown et al., 1997) and provides further evidence of impaired semantic access in WA. There are at least three potential sources of the reduced N400 responses in WA, each of which will be considered in turn: (1) impaired semantic processing, (2) impaired phonological perception, (3) impaired lexical retrieval.

All WA participants displayed a lesion affecting the middle temporal gyrus, a region associated with semantic processing (DeWitt \& Rauschecker, 2012; Harvey \& Schnur, 2015; Humphries, 
Binder et al., 2007; Indefrey \& Levelt, 2004; Krieger-Redwood \& Jefferies, 2014; Saur, Schelter et al., 2010) and seen to be modulated by the same experimental features as the $\mathrm{N} 400$ in functional imaging experiments (Lau, Phillips et al., 2008). Supporting the semantic hypothesis, greater N400 effects were identified in the WA group when semantic incongruency judgments were easier. This performance pattern differs from controls who produce greater N400 effects under more difficult processing conditions (Hagoort, Hald et al., 2004; Kuperberg, 2016). Therefore, these results may indicate coarser-grained semantic processing in WA, where incongruent items closely related to the target are not consistently distinguished from the target. Incongruent items with a looser relationship with the target may be more consistently processed as distinct and, therefore, more consistently generate N400 effects. This interpretation is supported by the behavioural performance, as all WA participants displayed greater accuracy in the semantic far condition than the semantic near condition. However, the same N400 and behavioural patterns were observed in the phonological conditions (greater N400 responses and behavioural accuracy for more distinct phonological distracters), indicating a similar coarseness of phonological analysis and lack of identification of incongruency status. These findings support the phonological hypothesis and the long-standing theory of WA that language comprehension is impaired because poor quality phonological analysis of the speech stream has a downstream impact on semantic access and analysis (Luria, 1976; Luria \& Hutton, 1977). Consistent with this hypothesis all the WA aphasia participants also displayed a lesion to the superior temporal sulcus, a region associated with phonological analysis (DeWitt \& Rauschecker, 2012; Harvey \& Schnur, 2015; Humphries, Binder et al., 2007; Indefrey \& Levelt, 2004; Krieger-Redwood \& Jefferies, 2014; Saur, Schelter et al., 2010). This hypothesis was further examined in the control population by artificially degrading the speech input using Saberi speech. N400 responses were significantly reduced under degraded listening conditions, indicating semantic processes were affected by quality of speech perception. This finding replicates previous N400 studies with neurotypical populations (Aydelott, Baer-Henney et al., 2012; Carey, Mercure et al., 2014; Strauß, Kotz et al., 2013) and supports the hypothesis 
that the reduced $\mathrm{N} 400$ responses found in WA group may be an indirect effect of a phonological perception impairment. A further explanation of reduced N400 responses in WA implicates poor lexical access. It is hypothesised that N400 effects occur when lexical access is more challenging and N400 responses are reduced when the context facilitates lexical access (Lau et al., 2008). The current study used a word-picture verification paradigm in which lexical context is established through picture stimuli activating corresponding lexical representations. It is highly likely that this lexical activation occurred more consistently and accurately in the control participants than the WA participants. This would result in a more challenging lexical access condition in response to incongruent words in the control group, as they would experience more priming towards the target than the WA group. It is likely that such a mechanism contributed to greater N400 responses in the control group; however, it is unclear that the lexical access hypothesis could account entirely for distance effects in the WA group. Given the extensive lesions observed in WA and the cognitive impairment profile, a combination of phonological, lexical and semantic processing impairments are likely to contribute to reduced N400 responses.

This study found some evidence for impaired speech perception/phonological processing during online comprehension in WA. No significant group-level PMN effects were observed in the WA, while the control group displayed PMN effects in both clear incongruent conditions. At the case series level, however, PMN responses were more inconsistent than N400 responses in both groups, resulting in no WA-control group difference. It is likely that impaired auditoryphonological analysis contributed to the lack of PMN responses in the WA group. This is supported by significantly reduced PMN responses in the control group under degraded listening conditions. However, the elicitation of a PMN is dependent on perceived phonological information violating contextual phonological expectations (Steinhauer \& Connolly, 2008). In the current word-picture verification experiment establishing an accurate phonological context depends on accurate lexical-phonological retrieval of the picture item - an impaired cognitive 
function in WA. Therefore a lack of accurate phonological context is likely to have significantly contributed to the PMN results in the WA group.

Finally, correlation analyses in the WA group found a significant relationship between wordpicture verification behavioural accuracy and PMN responses but not N400 responses. These results contrast with previous aphasia studies that have found greater comprehension accuracy to correspond to greater N400 amplitude (Hagoort, Brown et al., 1996; Swaab, Brown et al., 1997). However, this difference is likely to reflect different clinical populations; in the current study all participants displayed a WA profile rather than the mixed aphasia profiles of previous studies. Indeed, these neuropsychological correlations are similar to those identified in a previous study using offline measures of phonological and semantic processing (Robson, Keidel et al., 2012) and provide further evidence of the core impact of impaired phonological analysis on the comprehension impairment of WA.

\section{Conclusion:}

Using ERPs, this study investigated phonological and semantic processing during online comprehension in Wernicke's aphasia. Reduced N400 responses were identified in WA indicating impaired semantic access secondary to impairments in phonological perception, lexical access and semantic processing. This evidence converges with that obtained from offline neuropsychological and lesion data and, for the first time, demonstrates a direct link between speech perception and word comprehension during the comprehension process. 


\section{References:}

Arsenault, J. S., \& Buchsbaum, B. R. (2015). Distributed neural representations of phonological features during speech perception. The Journal of Neuroscience, 35(2), 634-642.

Aydelott, J., Baer-Henney, D., Trzaskowski, M., Leech, R., \& Dick, F. (2012). Sentence comprehension in competing speech: Dichotic sentence-word priming reveals hemispheric differences in auditory semantic processing. Language and Cognitive Processes, 27(7-8), 1108-1144.

Aydelott, J., Dick, F., \& Mills, D. L. (2006). Effects of acoustic distortion and semantic context on event-related potentials to spoken words. Psychophysiology, 43(5), 454-464.

Baggio, G., \& Hagoort, P. (2011). The balance between memory and unification in semantics: A dynamic account of the N400. Language and Cognitive Processes, 26(9), 1338-1367.

Bizley, J. K., \& Cohen, Y. E. (2013). The what, where and how of auditory-object perception. Nat Rev Neurosci, 14(10), 693-707.

Blumstein, S. E., Baker, E., \& Goodglass, H. (1977). Phonological factors in auditory comprehension in aphasia. Neuropsychologia, 15, 19-30.

Boersma, P., \& Weenink, D. (2009). Praat:Doing phonetics by computer (Version 5.1.05): http://praat.org.

Bogen, J. E., \& Bogen, G. M. (1976). Wernicke's region - Where is it? Annals of the New York Academy of Sciences, 280, 834-843.

Brouwer, H., \& Hoeks, J. C. (2013). A time and place for language comprehension: mapping the N400 and the P600 to a minimal cortical network. Frontiers in human neuroscience, 7(758), 1-12.

Carey, D., Mercure, E., Pizzioli, F., \& Aydelott, J. (2014). Auditory semantic processing in dichotic listening: Effects of competing speech, ear of presentation, and sentential bias on N400s to spoken words in context. Neuropsychologia, 65, 102-112.

Cohen, R., Kelter, S., \& Woll, G. (1980). Analytical competence and language impairment in aphasia. Brain and Language, 10, 331-351.

Connolly, J. F., \& Phillips, N. A. (1994). Event-Related Potential Components Reflect Phonological and Semantic Processing of the Terminal Word of Spoken Sentences. Journal of Cognitive Neuroscience, 6(3), 256-266.

Connolly, J. F., Phillips, N. A., Stewart, S. H., \& Brake, W. G. (1992). Event-related potential sensitivity to acoustic and semantic properties of terminal words in sentences. Brain and Language, 43(1), 1-18.

Desroches, A. S., Newman, R. L., \& Joanisse, M. F. (2008). Investigating the Time Course of Spoken Word Recognition: Electrophysiological Evidence for the Influences of Phonological Similarity. Journal of Cognitive Neuroscience, 21(10), 1893-1906.

DeWitt, I., \& Rauschecker, J. P. (2012). Phoneme and word recognition in the auditory ventral stream. Proceedings of the National Academy of Sciences, 109(8), E505-E514.

Divenyi, P. L., \& Robinson, A. J. (1989). Nonlinguistic auditory capabilities in aphasia. Brain and Language, 37(2), 290-326.

Fink, M., Churan, J., \& Wittmann, M. (2006). Temporal processing and context dependency of phoneme discrimination in patients with aphasia. Brain and Language, 98(1), 1-11.

Friederici, A. D. (2011). The Brain Basis of Language Processing: From Structure to Function. Physiological Reviews, 91(4), 1357-1392.

Gainotti, G., Silveri, M., C., Villa, G., \& Caltagirone, C. (1983). Drawing objects from memory in aphasia. Brain, 106, 613-622.

Giordano, B. L., McAdams, S., Zatorre, R. J., Kriegeskorte, N., \& Belin, P. (2012). Abstract Encoding of Auditory Objects in Cortical Activity Patterns. Cerebral Cortex.

Goodglass, H., Kaplan, E., \& Barresi, B. (2001a). The Assessment of Aphasia and Related Disorders

(3rd ed.). Baltimore: Lippincott Williams \&Wilkins.

Goodglass, H., Kaplan, E., \& Barresi, B. (2001b). Boston Diagnostic Aphasia Examination, 3rd Ed, (BDAE). Lippincott Williams \& Wilkins, Baltimore 
Hagoort, P., Brown, C. M., \& Swaab, T. Y. (1996). Lexical-semantic event-related potential effects in patients with left hemisphere lesions and aphasia, and patients with right hemisphere lesions without aphasia. Brain, 119(2), 627-649.

Hagoort, P., Hald, L., Bastiaansen, M., \& Petersson, K. M. (2004). Integration of word meaning and world knowledge in language comprehension. Science, 304(5669), 438-441.

Harvey, D. Y., \& Schnur, T. T. (2015). Distinct loci of lexical and semantic access deficits in aphasia: Evidence from voxel-based lesion-symptom mapping and diffusion tensor imaging. Cortex, 67, 37-58.

Hickok, G., \& Poeppel, D. (2007). The cortical organization of speech processing. Nature reviews. Neuroscience, 8(5), 393-402.

Hsieh, S., Schubert, S., Hoon, C., Mioshi, E., \& Hodges, J. R. (2013). Validation of the Addenbrooke's Cognitive Examination III in frontotemporal dementia and Alzheimer's disease. Dementia and geriatric cognitive disorders, 36(3-4), 242-250.

Humphries, C., Binder, J. R., Medler, D. A., \& Liebenthal, E. (2007). Time course of semantic processes during sentence comprehension: an fMRI study. NeuroImage, 36(3), 924-932.

Humphries, C., Sabri, M., Lewis, K., \& Liebenthal, E. (2014). Hierarchical organization of speech perception in human auditory cortex. Frontiers in Neuroscience, 8, 406.

Indefrey, P., \& Levelt, W. J. M. (2004). The spatial and temporal signatures of word production components. Cognition, 92, 101-144.

Kawohl, W., Bunse, S., Willmes, K., Hoffrogge, A., Buchner, H., \& Huber, W. (2009). Semantic Event-Related Potential Components Reflect Severity of Comprehension Deficits in Aphasia. Neurorehabilitation and Neural Repair.

Kiefer, M. (2002). The N400 is modulated by unconsciously perceived masked words: further evidence for an automatic spreading activation account of N400 priming effects. Cognitive Brain Research, 13(1), 27-39.

Krieger-Redwood, K., \& Jefferies, E. (2014). TMS interferes with lexical-semantic retrieval in left inferior frontal gyrus and posterior middle temporal gyrus: Evidence from cyclical picture naming. Neuropsychologia, 64, 24-32.

Kuperberg, G. R. (2016). Separate streams or probabilistic inference? What the N400 can tell us about the comprehension of events. Language, Cognition and Neuroscience, 1-15.

Kutas, M., \& Federmeier, K. D. (2011). Thirty years and counting: Finding meaning in the N400 component of the event related brain potential (ERP). Annual review of psychology, 62, 621.

Landauer, T. K., Foltz, P. W., \& Laham, D. (1998). An introduction to latent semantic analysis. Discourse processes, 25(2-3), 259-284.

Lau, E. F., Phillips, C., \& Poeppel, D. (2008). A cortical network for semantics: (de)constructing the N400. Nat Rev Neurosci, 9(12), 920-933.

Lee, T.-W., Girolami, M., \& Sejnowski, T. J. (1999). Independent component analysis using an extended infomax algorithm for mixed subgaussian and supergaussian sources. Neural computation, 11(2), 417-441.

Luria, A. R. (1976). Disturbances of Understanding of Verbal Communication in Patients with Sensory Aphasia. The Hague: Mouton \& Co. B. V.

Luria, A. R., \& Hutton, J. T. (1977). A modern assessment of the basic forms of aphasia. Brain and Language, 4, 129-151.

Marslen-Wilson, W. D. (1987). Functional parallelism in spoken word-recognition. Cognition, 25(1-2), 71-102.

McClelland, J. L., \& Elman, J. L. (1986). The TRACE model of speech perception. Cognitive psychology, 18(1), 1-86.

Newman, R. L., \& Connolly, J. F. (2009). Electrophysiological markers of pre-lexical speech processing: Evidence for bottom-up and top-down effects on spoken word processing. Biological Psychology, 80(1), 114-121.

Newman, R. L., Connolly, J. F., Service, E., \& McIvor, K. (2003). Influence of phonological expectations during a phoneme deletion task: Evidence from event-related brain potentials. Psychophysiology, 40(4), 640-647. 
Norris, D., \& McQueen, J. M. (2008). Shortlist B: a Bayesian model of continuous speech recognition. Psychological review, 115(2), 357.

Ogar, J. M., Baldo, J. V., Wilson, S. M., Brambati, S. M., Miller, B. L., Dronkers, N. F., \& GornoTempini, M. L. (2011). Semantic dementia and persisting Wernicke's aphasia: Linguistic and anatomical profiles. Brain and Language, 117(1), 28-33.

Robson, H., Cloutman, L., Keidel, J. L., Sage, K., Drakesmith, M., \& Welbourne, S. (2014). Mismatch negativity (MMN) reveals inefficient auditory ventral stream function in chronic auditory comprehension impairments. Cortex, 59(0), 113-125.

Robson, H., Grube, M., Lambon Ralph, M. A., Griffiths, T. D., \& Sage, K. (2013). Fundamental deficits of auditory perception in Wernicke's aphasia. Cortex, 49(7), 1808-1822.

Robson, H., Keidel, J. L., Lambon Ralph, M. A., \& Sage, K. (2012). Revealing and quantifying the impaired phonological analysis underpinning impaired comprehension in Wernicke's aphasia. Neuropsychologia, 50(2), 276-288.

Robson, H., Sage, K., \& Lambon Ralph, M. A. (2012). Wernicke's aphasia reflects a combination of acoustic-phonological and semantic control deficits: A case-series comparison of Wernicke's aphasia, semantic dementia and semantic aphasia. Neuropsychologia, 50(2), 266-275.

Rorden, C. (2007). MRIcron.

Rorden, C., Bonilha, L., Fridriksson, J., Bender, B., \& Karnath, H.-O. (2012). Age-specific CT and MRI templates for spatial normalization. NeuroImage, 61(4), 957-965.

Saberi, K., \& Perrott, D. R. (1999). Cognitive restoration of reversed speech. Nature, 398(6730), 760-760.

Saur, D., Schelter, B., Schnell, S., Kratochvil, D., Küpper, H., Kellmeyer, P., Kümmerer, D., Klöppel, S., Glauche, V., Lange, R., Mader, W., Feess, D., Timmer, J., \& Weiller, C. (2010). Combining functional and anatomical connectivity reveals brain networks for auditory language comprehension. NeuroImage, 49(4), 3187-3197.

Seghier, M. L., Ramlackhansingh, A., Crinion, J., Leff, A. P., \& Price, C. J. (2008). Lesion identification using unified segmentation-normalisation models and fuzzy clustering. NeuroImage, 41(4), 1253-1266.

Steinhauer, K., \& Connolly, J. F. (2008). Event-Related Potentials in the Study of Language. In S. B \& H. A. Whitaker (Eds.), Handbook of the Neuroscience of Language (First Edition ed., pp. 91-104). Amsterdam, The Netherlands: Elsevier.

Strauß, A., Kotz, S. A., \& Obleser, J. (2013). Narrowed Expectancies under Degraded Speech: Revisiting the N400. Journal of Cognitive Neuroscience, 25(8), 1383-1395.

Swaab, T., Brown, C., \& Hagoort, P. (1997). Spoken Sentence Comprehension in Aphasia: Eventrelated Potential Evidence for a Lexical Integration Deficit. Journal of Cognitive Neuroscience, 9(1), 39-66.

Teki, S., Barnes, G. R., Penny, W. D., Iverson, P., Woodhead, Z. V. J., Griffiths, T. D., \& Leff, A. P. (2013). The right hemisphere supports but does not replace left hemisphere auditory function in patients with persisting aphasia. Brain, 136(6), 1901-1912.

Van Den Brink, D., Brown, C. M., \& Hagoort, P. (2001). Electrophysiological evidence for early contextual influences during spoken-word recognition: N200 versus N400 effects. Journal of Cognitive Neuroscience, 13(7), 967-985.

Xu, G., Zhang, L., Shu, H., Wang, X., \& Li, P. (2013). Access to lexical meaning in pitch-flattened Chinese sentences: An fMRI study. Neuropsychologia, 51(3), 550-556. 